\title{
Copy number variations (CNVs) identified in Korean individuals Tae-Wook Kang ${ }^{\dagger 1}$, Yeo-Jin Jeon ${ }^{\dagger 1}$, Eunsu Jang ${ }^{\dagger 2}$, Hee-Jin Kim¹, Jeong- Hwan Kim¹, Jong-Lyul Park¹, Siwoo Lee ${ }^{2}$, Yong Sung Kim¹, Jong Yeol Kim*2 and Seon-Young Kim*1
}

Address: ${ }^{1}$ Medical Genomics Research Center, KRIBB, 52 Eoeun-dong, Yuseong-gu, Daejeon 305-806, Republic of Korea and ${ }^{2}$ Department of Medical Research, KIOM, 483 Expo-ro, Yuseong-gu, Daejeon 305-811, Republic of Korea

Email: Tae-Wook Kang - twkang76@kribb.re.kr; Yeo-Jin Jeon - jyj0242@kribb.re.kr; Eunsu Jang - esjang@kiom.re.kr; HeeJin Kim - dietk@hanmail.net; Jeong-Hwan Kim - alternaria@hanmail.net; Jong-Lyul Park - nlcguard@kribb.re.kr; Siwoo Lee - bfree@kiom.re.kr; Yong Sung Kim - yongsung@kribb.re.kr; Jong Yeol Kim* - ssmed@kiom.re.kr; Seon-Young Kim* - kimsy@kribb.re.kr

* Corresponding authors †Equal contributors

Published: 18 October 2008

BMC Genomics 2008, 9:492 doi:10.1/86/|47|-2/64-9-492
Received: 24 June 2008

Accepted: 18 October 2008

This article is available from: http://www.biomedcentral.com/I47I-2164/9/492

(C) 2008 Kang et al; licensee BioMed Central Ltd.

This is an Open Access article distributed under the terms of the Creative Commons Attribution License (http://creativecommons.org/licenses/by/2.0), which permits unrestricted use, distribution, and reproduction in any medium, provided the original work is properly cited.

\begin{abstract}
Background: Copy number variations (CNVs) are deletions, insertions, duplications, and more complex variations ranging from I $\mathrm{kb}$ to sub-microscopic sizes. Recent advances in array technologies have enabled researchers to identify a number of CNVs from normal individuals. However, the identification of new CNVs has not yet reached saturation, and more CNVs from diverse populations remain to be discovered.
\end{abstract}

Results: We identified 65 copy number variation regions (CNVRs) in 116 normal Korean individuals by analyzing Affymetrix $250 \mathrm{~K} \mathrm{Nsp}$ whole-genome SNP data. Ten of these CNVRs were novel and not present in the Database of Genomic Variants (DGV). To increase the specificity of CNV detection, three algorithms, CNAG, dChip and GEMCA, were applied to the data set, and only those regions recognized at least by two algorithms were identified as CNVs. Most CNVRs identified in the Korean population were rare (<1\%), occurring just once among the II 6 individuals. When CNVs from the Korean population were compared with CNVs from the three HapMap ethnic groups, African, European, and Asian; our Korean population showed the highest degree of overlap with the Asian population, as expected. However, the overlap was less than $40 \%$, implying that more CNVs remain to be discovered from the Asian population as well as from other populations. Genes in the novel CNVRs from the Korean population were enriched for genes involved in regulation and development processes.

Conclusion: $\mathrm{CNV}$ s are recently-recognized structural variations among individuals, and more $\mathrm{CNV}$ s need to be identified from diverse populations. Until now, CNVs from Asian populations have been studied less than those from European or American populations. In this regard, our study of CNVs from the Korean population will contribute to the full cataloguing of structural variation among diverse human populations. 


\section{Background}

Understanding variations in the human genome is the key to unraveling the phenotypic diversity among individuals and understanding various human diseases. Genomic variations exist at various levels, from differences in single nucleotides to microscopic chromosome-level variation [1]. Copy number variations (CNVs), a new type of genomic variation that has recently received considerable attention, are deletions, insertions, duplications, and more complex variations ranging from $1 \mathrm{~kb}$ to submicroscopic sizes [1-4]. Recent advances in array technologies such as BAC arrays, oligonucleotide array CGHs, and whole-genome SNP arrays, have finally enabled researchers to identify this new type of variation, which had gone unnoticed for a long time [5].

Since Sebat et al. [6] and Iafrate et al. [7] first reported large-scale CNVs among normal human individuals in 2004, and since then, many researchers have identified novel CNVs using diverse technical and computational approaches [8-17]. These reported CNVs are collected and maintained in a curated database, the database of genomic variants http://projects.tcag.ca/variation/, which contains more than $15,000 \mathrm{CNVs}$ obtained from 48 publications as of April, 2008. However, the discovery of new CNVs has not yet been saturated, and many challenges remain for the standardization of CNV discovery $[18,19]$. The global map of CNVs from the 270 normal individuals in the HapMap collection is an important advance in the field, yet genomes from more individuals from diverse populations should be studied to achieve a full cataloging of human CNVs [11].

Whole-genome SNP arrays such as Affymetrix $500 \mathrm{~K}$ or Illumina $300 \mathrm{~K}$ arrays, which are widely used for wholegenome association studies, are also useful for CNV discovery since the intensity of the probes can be exploited to detect CNV gains and losses [20-23]. A few recent studies successfully utilized whole-genome SNP data from control populations in North American and European countries for the detection of novel CNVs $[19,22,24,25]$. Here, we report the identification of 10 novel CNVs from 116 normal Korean individuals by analyzing Affymetrix 250 Nsp SNP array data. Our work will be valuable in expanding our knowledge of CNVs across diverse populations and ethnicities.

\section{Results and discussion CNVRs from the Korean population}

Commonly used algorithms for CNV detection from SNP arrays can produce widely different results from the same data because they differ both in the way reference samples are prepared and in their calling criteria $[19,26]$. A stringent criterion to select only regions identified by more than two different algorithms is currently recommended to increase confidence in the identified CNVs [19]. In this work, we applied three algorithms, CNAG [21], dChip [27] and GEMCA [20], to our data set of 116 normal Korean individuals genotyped using Affymetrix $250 \mathrm{~K} \mathrm{Nsp}$ arrays. We identified a total of 65 CNVRs, among which 10 CNVRs $(15.4 \%)$ were novel and not present in the Database of Genomic Variants. Many novel CNVs were likely missed by our approach, but we chose to be conservative in our selection of CNVs to reduce false positives. More than $15.4 \%$ of the identified CNVs in the Korean population would be novel if we consider a recent study, which showed that most CNV loci are actually smaller than currently recorded in the Database of Genomic Variants [28].

As expected, there were significant differences in the numbers and positions of CNVs identified by the three methods (Figure 1). In most cases, the dChip algorithm identified more CNVs than CNAG and GEMCA. Average 6.7, 3.5 and 2.6 CNVs per individual were found by dChip, CNAG and GEMCA, respectively (Additional file 1). In total, 772, 403 and $302 \mathrm{CNVs}$ were found by the dChip, CNAG and GEMCA algorithms. Detailed information for each identified CNV is shown in Additional file 2. A total of 141 CNVs was identified by our criterion of selecting CNVs represented by more than two algorithms. When we compared size distribution between 84 duplicated and 57 deleted CNVs (Additional file 2), we found that duplicated regions had a tendency to be longer than deleted regions $(\mathrm{p}<0.0009664, t$-test $)$. When we plotted each CNV in the genome, we found that most CNVs were located near the band of each chromosome (Figure 2). Finally, we defined 65 CNVRs from the 141 CNVs by merging overlapping CNVs from different individuals (Additional file 3 and 4).

\section{Size and occurrence of CNVs in the Korean population}

The sizes of the $141 \mathrm{CNVs}$ ranged from several kb to several megabases (Table 1). The smallest CNV was 15,723 $\mathrm{bp}$, and the largest 2,262,135 bp. Many CNVs were in the range of $10 \mathrm{~kb}$ to $300 \mathrm{~kb}$. We also compared the size distributions of the CNVs identified by each method. The smallest, median, and largest CNVs were 998, 153,137 and 2,264,086 bp for the GEMCA algorithm, 1,184, 267,962 and 23,992,731 bp for the CNAG algorithm and $641,67,372$ and 5,035,303 bp for the dChip. In general, CNVs identified by the dChip algorithm had larger range than those identified by the GEMCA and CNAG algorithms.

Most CNVs (75\%) from the Korean population were rare $(<1 \%)$, occurring just once among the 116 individuals (Table 2). However, a few previously reported CNVs occurred in a significant proportion of the Korean population. For instance, one CNV on chromosome 14 was 


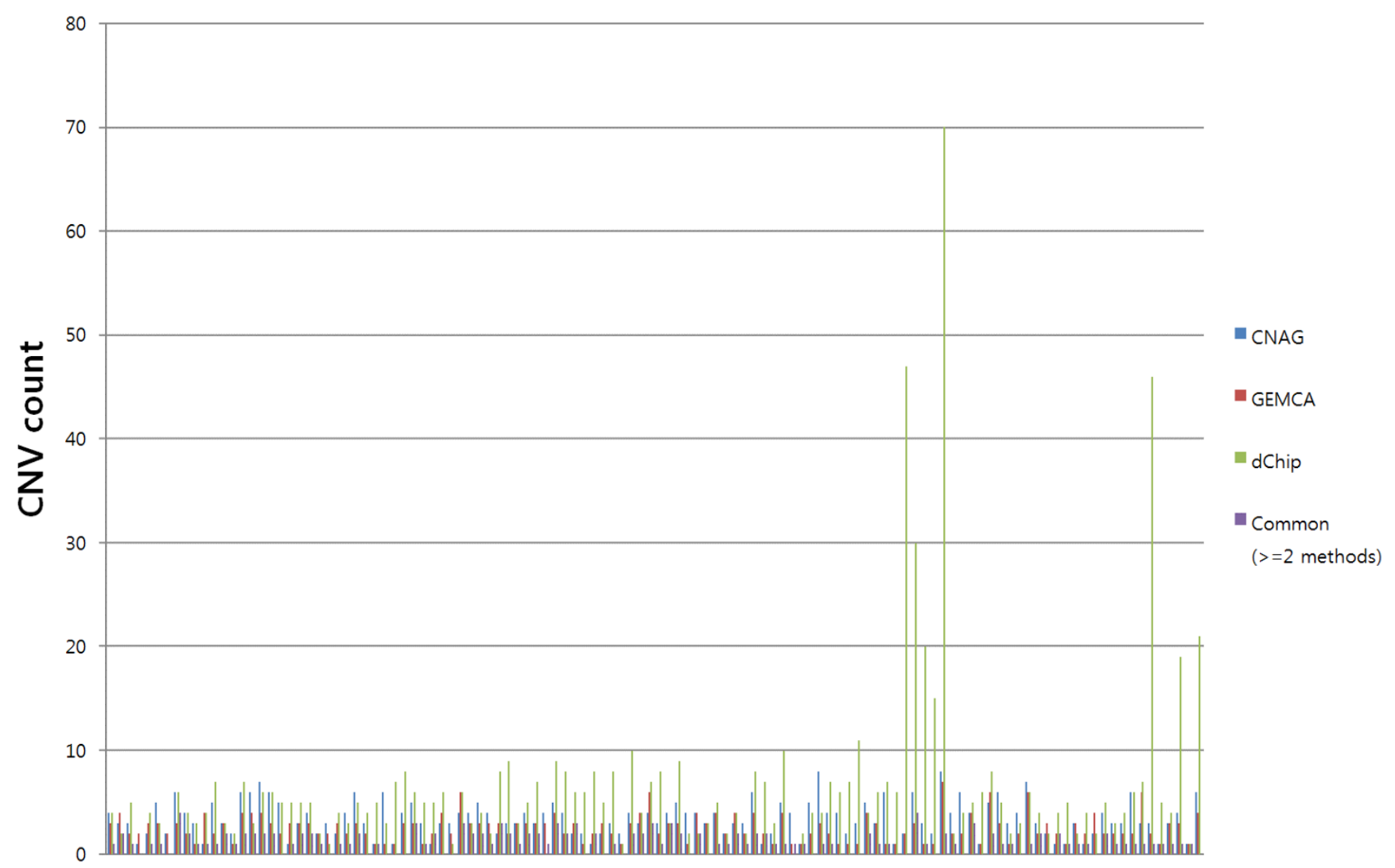

Individual

\section{Figure I}

Distribution of CNV counts identified using CNAG, dChip and GEMCA algorithms. Distribution of CNV counts in each individual. The $\mathrm{Y}$-axis represents the CNV count and the $\mathrm{X}$-axis represents each individual.

present in 31 individuals. Generally, there were more CNV gains than losses, and 5 (31\%) of the 16 CNVRs had mixed gains and losses among different individuals. Among all autosomal chromosomes, CNVs were detected most frequently on chromosomes 14, 15 and 8 .

\section{Comparison by ethnicity}

Affymetrix 500 K CEL files from the 270 HapMap individuals were obtained from the Affymetrix web site and analyzed with the CNAT algorithm to identify CNVs at an individual level. Also, individual-level CNV data from the 269 HapMap samples obtained by the array CGH method were downloaded from the copy number variation project at the Welcome Trust Sanger institute web site http:// www.sanger.ac.uk/humgen/cnv/data/cnv data/display/. The 270 individuals were divided into three ethnic groups - Asian (JPT + CHB), European (CEU), and African (YRI), and the overlap of CNVs between the Korean population and each of the three ethnic groups was investigated (Table 3). Overall, there was a $23-40 \%$ overlap in counts and a $23-79 \%$ overlap in actual nucleotides in CNVs between the Korean population and the three ethnic groups. The Korean population showed the highest degree of CNV overlap with the Asian population, as expected, but the overlap was less than $40 \%$, implying that many more CNVs remain to be identified from the Asian population beyond those identified in the 90 Asian HapMap individuals.

\section{Novel CNVRs from the Korean population}

Among the 10 novel CNVRs identified from the Korean population, 3 CNVRs contained a total of 5 genes (Additional file 5). The total length of the novel CNVRs was $1,788,129 \mathrm{bp}$, or $0.06 \%$ of the human genome. The total 


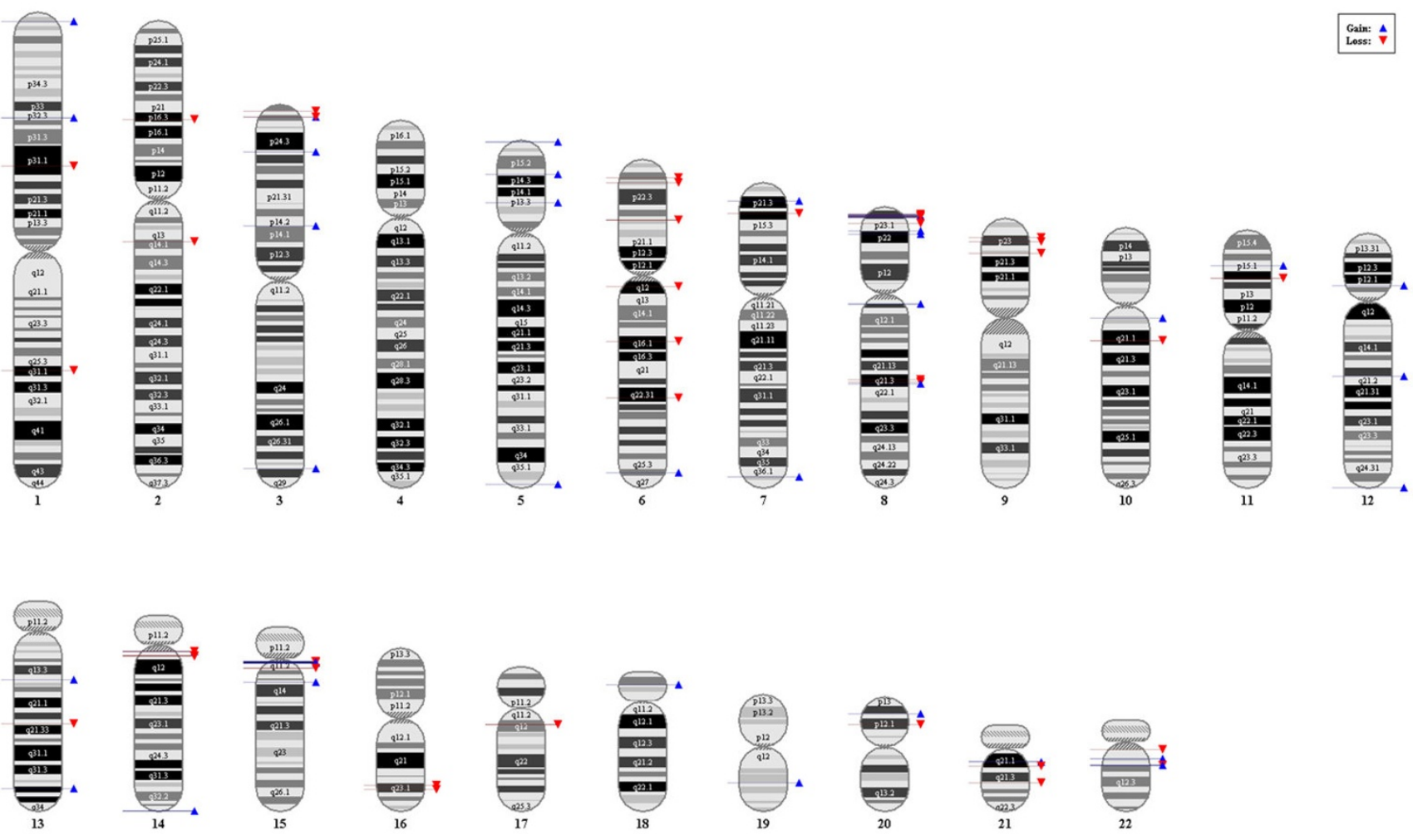

Figure 2

Distribution and frequencies of CNVs identified in Korean population in the human genome. The blue triangle indicates gains and the red inverted triangle indicates losses, respectively.

length of the 55 known CNVRs is $14,280,140$ bp $(0.48 \%$ of the human genome). Twenty-four of these CNVRs contained 52 genes.

Among the three novel CNVRs, we validated two CNVRs by Q-PCR (Figure 3). One case sample, which had a gain of two copies in a novel CNVR encompassing SYNPR gene, showed a 3.59-fold increase in DNA copy number in comparison to five samples with normal copy number (Figure 3A). The other validated region was a CNVR containing KRR1 gene, In this case, the case sample, which

Table I: Distribution of CNV sizes identified in the Korean population

\begin{tabular}{rrrr}
\hline Size (bp) & Novel CNV & Known CNV & Sum \\
\hline $10 \mathrm{~K}-100 \mathrm{~K}$ & 3 & 33 & 36 \\
$100 \mathrm{~K}-200 \mathrm{~K}$ & 3 & 58 & 61 \\
$200 \mathrm{~K}-300 \mathrm{~K}$ & 3 & 8 & 11 \\
$300 \mathrm{~K}-400 \mathrm{~K}$ & 0 & 8 & 8 \\
$400 \mathrm{~K}-500 \mathrm{~K}$ & 1 & 4 & 5 \\
$500 \mathrm{~K}-1 \mathrm{M}$ & 0 & 7 & 7 \\
I M-10 M & 0 & 13 & 13 \\
Total & 10 & 131 & 141 \\
\hline
\end{tabular}

had a gain of one copy, showed a 1.86-fold increase in DNA copy number in comparison to five samples with normal copy number (Figure 3B).

We analyzed the functional enrichment of genes contained in the CNVRs from the Korean population using

Table 2: Occurrence of CNVs among the Korean population

\begin{tabular}{rrrr}
\hline Occurrence & Novel CNV & Known CNV & Sum \\
\hline 1 & 10 & 39 & 49 \\
2 & 0 & 7 & 7 \\
3 & 0 & 2 & 2 \\
4 & 0 & 2 & 2 \\
5 & 0 & 1 & 1 \\
6 & 0 & 0 & 0 \\
7 & 0 & 2 & 2 \\
8 & 0 & 0 & 0 \\
9 & 0 & 0 & 0 \\
10 & 0 & 0 & 0 \\
$11-20$ & 0 & 1 & 1 \\
$21-30$ & 0 & 0 & 0 \\
$31-40$ & 0 & 1 & 1 \\
\hline Total & 10 & 55 & 65
\end{tabular}


Table 3: Overlap between CNVs from the Korean population and CNVs from the 270 HapMap individuals

\begin{tabular}{|c|c|c|c|c|c|c|c|c|}
\hline Ethnicity & $\begin{array}{l}\text { HAP* CNV } \\
\text { count }\end{array}$ & $\begin{array}{l}\text { HAP CNVR } \\
\text { count }\end{array}$ & $\begin{array}{l}\text { HAP CNV } \\
\text { size (bP) }\end{array}$ & $\begin{array}{l}\text { KOR\# unique } \\
\text { count }\end{array}$ & $\begin{array}{l}\text { KOR-HAP } \\
\text { overlap count }\end{array}$ & $\begin{array}{l}\text { KOR-HAP } \\
\text { overlap size } \\
\text { (bp) }\end{array}$ & $\begin{array}{l}\text { KOR-HAP } \\
\text { overlap count } \\
\text { percent }\end{array}$ & $\begin{array}{l}\text { KOR-HAP } \\
\text { overlap size } \\
\text { percent }\end{array}$ \\
\hline \multicolumn{9}{|c|}{ A. Affymetrix $500 \mathrm{~K}$} \\
\hline $\mathrm{CHB}+\mathrm{JPT}$ & 1,957 & 593 & $394,995,510$ & 39 & 26 & $7,326,74 \mid$ & $40.00 \%$ & $45.60 \%$ \\
\hline CEU & $\mathrm{I}, 700$ & 305 & $231,661,002$ & 50 & 15 & $3,634,120$ & $23.08 \%$ & $22.62 \%$ \\
\hline YRI & 1,627 & 318 & $236,857,444$ & 45 & 20 & $4,576,087$ & $30.77 \%$ & $28.48 \%$ \\
\hline \multicolumn{9}{|l|}{ B. WGTP } \\
\hline $\mathrm{CHB}+\mathrm{JPT}$ & 5,753 & 990 & $361,340,796$ & 42 & 23 & $12,679,720$ & $35.38 \%$ & $78.91 \%$ \\
\hline CEU & 5,597 & 970 & $358,358,246$ & 50 & 15 & $6,486,626$ & $23.08 \%$ & $40.37 \%$ \\
\hline YRI & 7,280 & 469 & $|70,54|, 572$ & 46 & 19 & $4,482,724$ & $29.23 \%$ & $27.90 \%$ \\
\hline
\end{tabular}

*HAP: HapMap individuals.

\#KOR: Korean population

the GOstat tool (Table 4 and 5) [29]. The novel CNVRs were enriched with genes involved in regulation and development processes (Table 4). Genes in the previously known CNVRs were mainly related to processes such as cell adhesion, multicellular, development, and regulation of gene expression (Table 5). Our results are in agreement with Nguyen et al.'s work, which showed the over-representation of secreted, cell adhesion, and immunity-related proteins in CNV-associated genes [30].

The fact that $15 \%(10 / 65)$ of CNVs in the Korean population were novel implies that current $\mathrm{CNV}$ discovery has not yet plateaued, and that the genomes of more individ- uals should be examined to fully understand CNVs in the general population. Until recently, CNV studies have mainly focused on populations in North America and Europe $[19,25]$. More individuals from other continents, such as Asia, Africa, and South America, need to be studied to enrich our understanding of the diversity of CNVs in the human population. We stress that the Korean population had less than a $40 \%$ overlap in CNVRs with the 90 Asian HapMap individuals, which suggests that more individuals should be studied to fully represent the pattern of CNVs among East Asian populations. In this regard, our work on 116 Korean individuals will be a use-
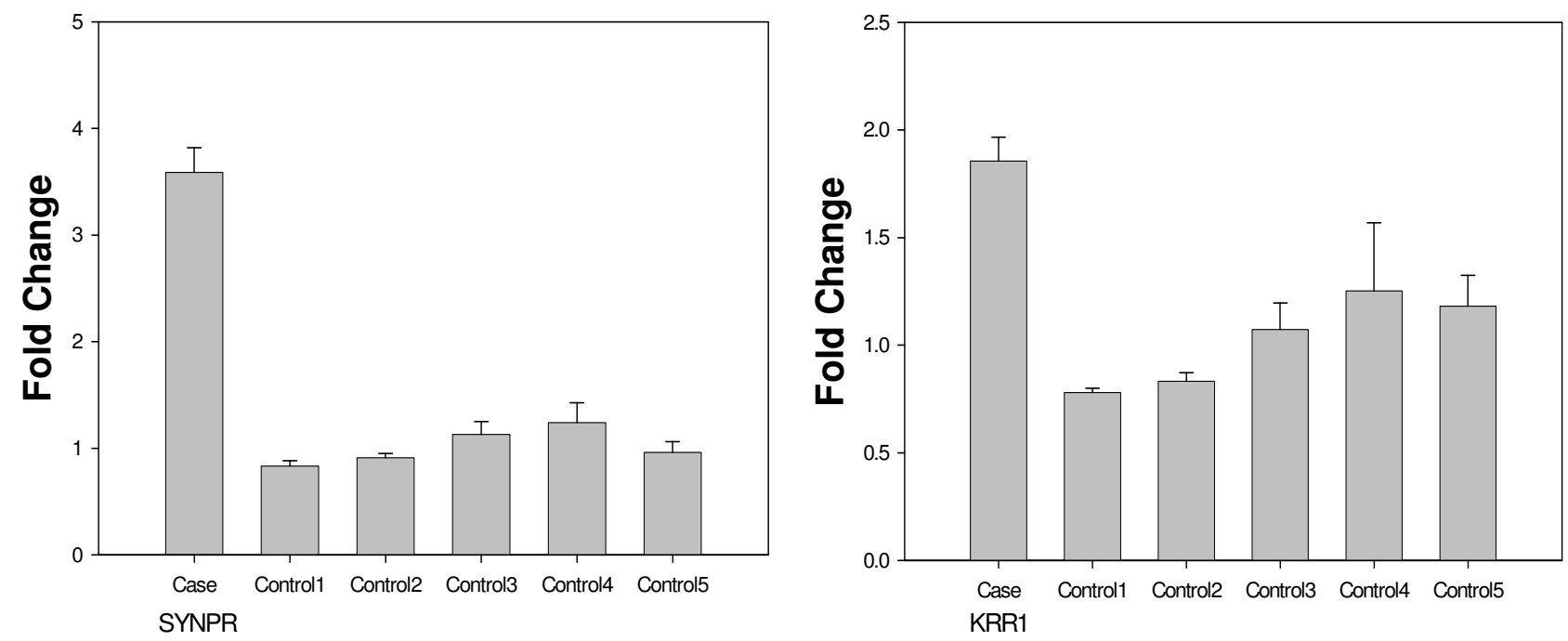

Figure 3

Validation of two novel CNVRs by Q-PCR. (A) SYNPR, (B) KRRI. For each gene, one case (with a CNVR) and five normal controls were compared by Q-PCR. The mean of five control samples was arbitrarily set to I and each sample was compared to the mean value. Each bar and error bar represents a mean and standard deviation of relative expression values from triplicate experiments. 
Table 4: Functional annotation of novel CNVs from the Korean population

\begin{tabular}{|c|c|c|c|c|}
\hline GO id & Group count & Total count & P-value & GO terms \\
\hline GO:0045995 & 1 & 8 & 0.033 & regulation of embryonic development \\
\hline GO:0050679 & 1 & 18 & 0.0333 & positive regulation of epithelial cell proliferation \\
\hline GO:0050678 & 1 & 30 & 0.0333 & regulation of epithelial cell proliferation \\
\hline GO:0050673 & I & 33 & 0.0333 & epithelial cell proliferation \\
\hline GO:0030334 & 1 & 60 & 0.0333 & regulation of cell migration \\
\hline GO:0030155 & 1 & 66 & 0.0333 & regulation of cell adhesion \\
\hline GO:005I 270 & I & 69 & 0.0333 & regulation of cell motility \\
\hline GO:0040012 & 1 & 72 & 0.0333 & regulation of locomotion \\
\hline GO:00400II & 1 & 73 & 0.0333 & locomotion \\
\hline GO:0016477 & 1 & 233 & 0.0738 & cell migration \\
\hline GO:0008284 & I & 233 & 0.0738 & positive regulation of cell proliferation \\
\hline GO:0009790 & 1 & 235 & 0.0738 & embryonic development \\
\hline GO:0050793 & I & 236 & 0.0738 & regulation of developmental process \\
\hline
\end{tabular}

ful resource for better understanding the diverse variation in the human genome.

\section{Conclusion}

Recent studies have shown that CNVs are as important as single nucleotide polymorphisms (SNPs) or microscopic variations. Many studies have reported the identification of novel CNVs, but more CNVs from diverse populations should be identified until we have a full catalogue of the structural variations among human populations. Until now, the CNVs of Asian populations have not been as thoroughly studied as those of European or American populations, and in this regard our study of CNVs from the Korean population will contribute to the full cataloguing of structural variations among diverse human populations.

\section{Methods \\ DNA samples}

Blood specimens were obtained from normal, healthy subjects who visited the Korean Institute of Oriental Medicine (KIOM) and collaborative hospitals. The internal review board at KIOM approved study protocols and informed consent was obtained from all enrolled study subjects. Genomic DNA was extracted from blood samples using the QIAamp DNA Blood Maxi Kit (Qiagen, Valencia, CA) according to the manufacturer's instruction. DNA concentration and purity were determined using the NanoDrop DN-1000 spectrophotometer (NanoDrop Technologies, Rockland, DE).

Table 5: Functional annotation of known CNVs from the Korean population

\begin{tabular}{|c|c|c|c|c|}
\hline GO id & Group count & Total count & P-value & GO terms \\
\hline GO:0007565 & 5 & 81 & $7.62 \mathrm{E}-06$ & female pregnancy \\
\hline GO:0007608 & 7 & 540 & 0.000303 & sensory perception of smell \\
\hline GO:0007606 & 7 & 584 & 0.000336 & sensory perception of chemical stimulus \\
\hline GO:00224I4 & 5 & 305 & 0.00128 & reproductive process \\
\hline GO:005I704 & 5 & 333 & 0.00156 & multi-organism process \\
\hline GO:0007600 & 7 & 950 & 0.00365 & sensory perception \\
\hline GO:0007I65 & 15 & 5142 & 0.0117 & signal transduction \\
\hline GO:0007I66 & 10 & 2433 & 0.0117 & cell surface receptor linked signal transduction \\
\hline GO:0050877 & 7 & 1269 & 0.0134 & neurological system process \\
\hline GO:0007/86 & 8 & 1677 & 0.0134 & G-protein coupled receptor protein signaling pathway \\
\hline GO:0007I54 & 15 & 5560 & 0.0237 & cell communication \\
\hline GO:0006433 & I & 2 & 0.0264 & prolyl-tRNA aminoacylation \\
\hline GO:0003008 & 7 & 1539 & 0.0286 & system process \\
\hline GO:0017000 & I & 3 & 0.0339 & antibiotic biosynthetic process \\
\hline GO:0016999 & I & 4 & 0.0421 & antibiotic metabolic process \\
\hline GO:0009649 & I & 5 & 0.0493 & entrainment of circadian clock \\
\hline GO:0007I85 & I & 6 & 0.0498 & transmembrane receptor protein tyrosine phosphatase signaling pathway \\
\hline GO:0006426 & I & 6 & 0.0498 & glycyl-tRNA aminoacylation \\
\hline GO:0017144 & I & 6 & 0.0498 & drug metabolic process \\
\hline
\end{tabular}




\section{Affymetrix GeneChip Nsp 250 K Mapping Array data} The $250 \mathrm{KNsp}$ mapping assay was performed according to the manufacturer's protocol. Briefly, DNA (250 ng) was digested with NspI (NEB, MA) and then ligated with an NspI linker supplied by Affymetrix. The ligated DNA was diluted four-fold and PCR-amplified using a PCR primer complementary to the linker DNA. The PCR products were purified using a DNA Amplification Clean-Up Kit (Clontech, CA) and $90 \mu \mathrm{g}$ of the PCR products were fragmented by DNase I treatment. The fragmented DNA was labelled using $0.86 \mathrm{mM}$ GeneChip DNA labelling reagents (Affymetrix) and $1.5 \mathrm{U} / \mu \mathrm{l}$ terminal deoxy-nucleotidyl transferase $(\mathrm{TdT})$ for $4 \mathrm{hr}$ at $37^{\circ} \mathrm{C}$, while the remaining 4.5 $\mu \mathrm{l}$ was examined on $4 \%$ TBE agarose gel to confirm that average DNA fragment size was $<180 \mathrm{bp}$. Hybridization and subsequent steps were performed according to the manufacturer's instructions. Hybridization experiments that passed the genotyping call rate over $93 \%$ by the dynamic model algorithm were used in the subsequent analysis to reduce false positive predictions arising from low quality genotyping data.

\section{Copy number analysis using CNAG, dChip and GEMCA} Three algorithms, CNAG (version 2.0), GEMCA (available at http://www2.genome.rcast.u-tokyo.ac.jp/CNV/ gemca details.html) and dChip, were used to infer copy numbers from $250 \mathrm{~K}$ Nsp SNP array data.

A reference data set of 48 normal individuals (obtained from the Affymetrix website) was used in the non-paired reference analysis with default parameters and CNVs inferred as more than two consecutive SNPs in CNAG analysis. In the GEMCA analysis, a reference data set of 10 normal individuals was used in the non-paired reference analysis and the default parameters were used. The boundary of CNVs was determined using 90\% density borders [20]. Analysis with dChip was normalized at the probe intensity level with an invariant set normalization method [27]. A signal value was calculated for each SNP using an average model method (PM/MM difference). From the raw copy numbers, the inferred copy number was estimated by using HMM (Hidden Markov model) and $10 \%$ of sample trimmed options and CNVs were inferred as more than two consecutive SNPs. Finally, for each individual, $\mathrm{CNV}$ s were defined as a region identified by more than two algorithms (overlap rate $>=50 \%$, length $>=1000 \mathrm{bp}$ ). This strategy is likely to increase a confidence in the detected CNVs although many novel CNVs may be missed [19]. Considering the current lack of standards in CNV discovery methods, we think that a more stringent approach like ours is appropriate. NCBI genome build 36 (hg18) was used to map each CNV to its genomic position.

\section{Comparison of Korean CNVs with those of 270 HapMap individuals}

CEL files for the 270 HapMap individuals were downloaded from the Affymetrix web site. For copy number analysis of the 270 HapMap samples, the same reference set of 48 samples was used in the CNAT analysis. CNV data for each of the 269 HapMap individuals investigated using the whole genome TilePath (WGTP) array was downloaded from the CNV Project web site at the Welcome Trust Sanger Institute http://www.sanger.ac.uk/ humgen/cnv/[11].

\section{Determination of novel CNVRs and functional annotation analysis}

CNVs identified in our Korean population were compared with 11,966 CNVs in the Database of Genomic Variants (downloaded as of Feb. 2008). The GOstat web service was used for gene ontology (GO) term analysis to study the enrichment of GO terms in the known and novel CNVs [29]. This analysis was performed with the default option for biological processes and the GO term candidates were ordered by p-value.

\section{Quantitative-PCR (Q-PCR) for CNVs validation}

Two selected novel CNVs were validated by Q-PCR. QPCR was done in $20 \mu \mathrm{l}$ with the following components: $7.0 \mu \mathrm{l}$ of molecular biology grade water (Hyclone, US), 10 $\mu \mathrm{l}$ of $2 \times$ SYBR Green Premix EX Taq solution, $0.5 \mu \mathrm{l}$ of forward and reverse primers ( $10 \mathrm{pmol} / \mu \mathrm{l}$ each $)$ and $2 \mu \mathrm{l} \mathrm{tem-}$ plate DNA $(1 \mathrm{ng} / \mathrm{ml})$. Primer sequences were $5^{\prime}$ AGCCAGCTATCAGGTGAGGA-3' (SYNPR-forward), 5'ACTTGTCTAAGCCCCTGCAA-3' (SYNPR-reverse), 5'GAGTGGGCTTTGTGGTGAAT-3' (KRR1-forward) and 5'TGTGCTGGGCATATTAGTGG-3' (KRR1-reverse). Q-PCR was conducted using CFX96 (Bio-Rad Laboratories, US) with the following cycling condition: initial denaturation at $95^{\circ} \mathrm{C}$ for $3 \mathrm{~min}$ followed by 45 cycles of $95^{\circ} \mathrm{C}$ for $10 \mathrm{~s}$, $60^{\circ} \mathrm{C}$ for $20 \mathrm{~s}$ and and $72^{\circ} \mathrm{C}$ for $20 \mathrm{~s}$. The relative quantification in each sample was determined.

\section{Authors' contributions}

SL and HYP collected blood samples and prepared DNA. $\mathrm{HJK}$ and JHK performed genotyping experiments. JHK and JYP performed RT-PCR experiments. TWK, YJJ, and SYK performed bioinformatics analyses. TWK, YJJ, SYK, JYK and YSK wrote the manuscript. All authors read and approved the manuscript. 


\section{Additional material}

\section{Additional file 1}

Comparison of CNV counts between CNAG, dChip and GEMCA algorithms in 116 Korean individuals.

Click here for file

[http://www.biomedcentral.com/content/supplementary/1471-

2164-9-492-S1.xls]

\section{Additional file 2}

Detailed information on individual CNVs identified using the CNAG, dChip and GEMCA algorithms. NCBI genome build 36 was used for chromosomal positions.

Click here for file

[http://www.biomedcentral.com/content/supplementary/14712164-9-492-S2.xls]

\section{Additional file 3}

Identification of intersected CNVs between the CNAG, dChip and GEMCA algorithms.

Click here for file

[http://www.biomedcentral.com/content/supplementary/1471-

2164-9-492-S3.xls]

\section{Additional file 4}

Detailed information on CNVRs identified from the Korean population.

Click here for file

[http://www.biomedcentral.com/content/supplementary/1471-

2164-9-492-S4.xls]

\section{Additional file 5}

A list of genes contained in CNVRs identified from the Korean population.

Click here for file

[http://www.biomedcentral.com/content/supplementary/14712164-9-492-S5.xls]

\section{Acknowledgements}

This work was supported by a grant NBC19007I2 (to YSK) from the Ministry of Science and Technology of Korea and KRIBB Research Initiative program.

\section{References}

I. Sharp AJ, Cheng Z, Eichler EE: Structural variation of the human genome. Annu Rev Genomics Hum Genet 2006, 7:407-442.

2. Feuk L, Carson AR, Scherer SW: Structural variation in the human genome. Nat Rev Genet 2006, 7(2):85-97.

3. Feuk L, Marshall CR, Wintle RF, Scherer SW: Structural variants: changing the landscape of chromosomes and design of disease studies. Hum Mol Genet 2006, I5(Spec No I):R57-66.

4. Freeman JL, Perry GH, Feuk L, Redon R, McCarroll SA, Altshuler DM, Aburatani $\mathrm{H}$, Jones KW, Tyler-Smith $\mathrm{C}$, Hurles ME, et al:: Copy number variation: new insights in genome diversity. Genome Res 2006, 16(8):949-961.

5. Carter NP: Methods and strategies for analyzing copy number variation using DNA microarrays. Nat Genet 2007, $39(7$ Suppl):SI6-2I.

6. Sebat J, Lakshmi B, Troge J, Alexander J, Young J, Lundin P, Maner S, Massa H, Walker M, Chi M, et al.: Large-scale copy number polymorphism in the human genome. Science 2004 , 305(5683):525-528.
7. lafrate AJ, Feuk L, Rivera MN, Listewnik ML, Donahoe PK, Qi Y, Scherer SW, Lee C: Detection of large-scale variation in the human genome. Nat Genet 2004, 36(9):949-95I.

8. Sharp AJ, Locke DP, McGrath SD, Cheng Z, Bailey JA, Vallente RU, Pertz LM, Clark RA, Schwartz S, Segraves R, et al.: Segmental duplications and copy-number variation in the human genome. Am J Hum Genet 2005, 77(I):78-88.

9. Tuzun E, Sharp AJ, Bailey JA, Kaul R, Morrison VA, Pertz LM, Haugen E, Hayden H, Albertson D, Pinkel D, et al.: Fine-scale structural variation of the human genome. Nat Genet 2005, 37(7):727-732.

10. Conrad DF, Andrews TD, Carter NP, Hurles ME, Pritchard JK: A high-resolution survey of deletion polymorphism in the human genome. Nat Genet 2006, 38(I):75-8I.

II. Redon R, Ishikawa S, Fitch KR, Feuk L, Perry GH, Andrews TD, Fiegler $\mathrm{H}$, Shapero $\mathrm{MH}$, Carson AR, Chen W, et al.: Global variation in copy number in the human genome. Nature 2006, 444(7 I I 8):444-454.

12. Kriek M, White SJ, Szuhai K, Knijnenburg J, van Ommen GJ, den Dunnen JT, Breuning MH: Copy number variation in regions flanked (or unflanked) by duplicons among patients with developmental delay and/or congenital malformations; detection of reciprocal and partial Williams-Beuren duplications. Eur J Hum Genet 2006, 14(2): 180-189.

13. Fiegler H, Redon R, Andrews D, Scott C, Andrews R, Carder C, Clark $R$, Dovey $O$, Ellis $P$, Feuk $L$, et al.: Accurate and reliable highthroughput detection of copy number variation in the human genome. Genome Res 2006, 16(12):1566-1574.

14. Khaja R, Zhang J, MacDonald JR, He Y, Joseph-George AM, Wei J, Rafiq MA, Qian C, Shago M, Pantano L, et al:: Genome assembly comparison identifies structural variants in the human genome. Nat Genet 2006, 38(I 2): |4|3-14|8.

15. Locke DP, Sharp AJ, McCarroll SA, McGrath SD, Newman TL, Cheng Z, Schwartz S, Albertson DG, Pinkel D, Altshuler DM, et al.: Linkage disequilibrium and heritability of copy-number polymorphisms within duplicated regions of the human genome. Am J Hum Genet 2006, 79(2):275-290.

16. McCarroll SA, Hadnott TN, Perry GH, Sabeti PC, Zody MC, Barrett JC, Dallaire S, Gabriel SB, Lee C, Daly MJ, et al.: Common deletion polymorphisms in the human genome. Nat Genet 2006, 38(I):86-92.

17. Qiao Y, Liu X, Harvard C, Nolin SL, Brown WT, Koochek M, Holden J], Lewis ME, Rajcan-Separovic E: Large-scale copy number variants (CNVs): distribution in normal subjects and FISH/realtime qPCR analysis. BMC Genomics 2007, 8: 167.

18. Scherer SW, Lee C, Birney E, Altshuler DM, Eichler EE, Carter NP, Hurles ME, Feuk $L$ : Challenges and standards in integrating surveys of structural variation. Nat Genet 2007, 39(7 Suppl):S7-I5.

19. Pinto D, Marshall C, Feuk L, Scherer SW: Copy-number variation in control population cohorts. Hum Mol Genet 2007, 16(Spec No 2): RI68-173.

20. Komura D, Shen F, Ishikawa S, Fitch KR, Chen W, Zhang J, Liu G, Ihara $S$, Nakamura $H$, Hurles ME, et al.: Genome-wide detection of human copy number variations using high-density DNA oligonucleotide arrays. Genome Res 2006, I6(I2): I575-I584.

21. Nannya Y, Sanada M, Nakazaki K, Hosoya N, Wang L, Hangaishi A, Kurokawa M, Chiba S, Bailey DK, Kennedy GC, et al.: A robust algorithm for copy number detection using high-density oligonucleotide single nucleotide polymorphism genotyping arrays. Cancer Res 2005, 65( (14):607|-6079.

22. Simon-Sanchez J, Scholz S, Fung HC, Matarin M, Hernandez D, Gibbs JR, Britton A, de Vrieze FW, Peckham E, Gwinn-Hardy K, et al.: Genome-wide SNP assay reveals structural genomic variation, extended homozygosity and cell-line induced alterations in normal individuals. Hum Mol Genet 2007, I6(I): I-I4.

23. Peiffer DA, Le JM, Steemers FJ, Chang W, Jenniges T, Garcia F, Haden $\mathrm{K}$, Li J, Shaw CA, Belmont J, et al.: High-resolution genomic profiling of chromosomal aberrations using Infinium wholegenome genotyping. Genome Res 2006, 16(9): I I36-II 48.

24. Wong KK, deLeeuw RJ, Dosanjh NS, Kimm LR, Cheng Z, Horsman $\mathrm{DE}$, MacAulay C, Ng RT, Brown CJ, Eichler EE, et al.: A comprehensive analysis of common copy-number variations in the human genome. Am J Hum Genet 2007, 80(I):91-104.

25. Zogopoulos G, Ha KC, Naqib F, Moore S, Kim H, Montpetit A, Robidoux F, Laflamme P, Cotterchio M, Greenwood C, et al.: Germ-line DNA copy number variation frequencies in a large North American population. Hum Genet 2007, I 22(3-4):345-353. 
26. Baross A, Delaney AD, Li HI, Nayar T, Flibotte S, Qian H, Chan SY, Asano J, Ally A, Cao M, et al.: Assessment of algorithms for high throughput detection of genomic copy number variation in oligonucleotide microarray data. BMC Bioinformatics 2007, 8:368.

27. Lin M, Wei LJ, Sellers WR, Lieberfarb M, Wong WH, Li C: dChipSNP: significance curve and clustering of SNP-array-based loss-of-heterozygosity data. Bioinformatics 2004, 20(8): $1233-1240$.

28. Perry GH, Ben-Dor A, Tsalenko A, Sampas N, Rodriguez-Revenga L Tran CW, Scheffer A, Steinfeld I, Tsang P, Yamada NA, et al: The fine-scale and complex architecture of human copy-number variation. Am J Hum Genet 2008, 82(3):685-695.

29. Beissbarth T, Speed TP: GOstat: find statistically overrepresented Gene Ontologies within a group of genes. Bioinformatics 2004, 20(9): | 464-| 465.

30. Nguyen DQ, Webber C, Ponting CP: Bias of selection on human copy-number variants. PLoS Genet 2006, 2(2):e20.

Publish with Bio Med Central and every scientist can read your work free of charge

"BioMed Central will be the most significant development for disseminating the results of biomedical research in our lifetime. "

Sir Paul Nurse, Cancer Research UK

Your research papers will be:

- available free of charge to the entire biomedical community

- peer reviewed and published immediately upon acceptance

- cited in PubMed and archived on PubMed Central

- yours - you keep the copyright

Submit your manuscript here:

http://www.biomedcentral.com/info/publishing_adv.asp 